\title{
Characterisation of the hydraulic maldistribution in a heat exchanger by local measurement of convective heat transfer coefficients using infrared thermography
}

\author{
P. Leblay ${ }^{b}$, J.-F. Henry ${ }^{b}$, D. Caron ${ }^{b}$, D. Leducq ${ }^{a, *}$, L. Fournaison ${ }^{a}$, \\ A. Bontemps ${ }^{c}$

\footnotetext{
${ }^{a}$ LGP2ES Irstea-GPAN, 1, rue Pierre-Gilles de Gennes, CS 10030, 92761 Antony Cedex, France

${ }^{\mathrm{b}}$ University of Reims Champagne-Ardenne, URCA/GRESPI/Thermomécanique, UFR Sciences, 51687 Reims, France

${ }^{c}$ LEGI, UMR 5519, Domaine Universitaire BP 53, 38041 Grenoble Cedex 9, France
}

\begin{abstract}
A methodology was developed to characterise the heat exchangers' performance decrease due to two-phase flow maldistribution. It consists in measuring the spatial distribution of the local heat transfer coefficients with a rapid, non-invasive and fluid independent method. The method is based on the infrared (IR) thermography measurement of the temperature response to an oscillating heat flux. The amplitude of the measured temperatures is compared to the solution of an analytical model. The problem is solved iteratively to obtain the heat transfer coefficients. This method has been applied to evaluate the uneven phase distribution of an air-water mixture in a compact heat exchanger. The exchanger is composed of seven multiport flat tubes, a vertical downward header and horizontal channels. Experiments were performed for mass flux from $29 \mathrm{~kg} \mathrm{~m}^{-2} \mathrm{~s}^{-1}$ to $116 \mathrm{~kg} \mathrm{~m}^{-2} \mathrm{~s}^{-1}$ and for quality from 0.10 to 0.70 .
\end{abstract}




\section{Nomenclature}

a thermal diffusivity $a=k /\left(\rho c_{p}\right), \mathrm{m}^{2} \mathrm{~s}^{-1}$

$c_{p} \quad$ specific heat capacity, $\mathrm{J} \mathrm{kg}^{-1} \mathrm{~K}^{-1}$

$D_{\mathrm{h}} \quad$ hydraulic diameter, $\mathrm{m}$

$f$ frequency, $\mathrm{Hz}$

$f \quad$ friction factor

G mass flux, kg.m ${ }^{-2} \mathrm{~s}^{-1}$

$\mathrm{H}$ height, $\mathrm{m}$

h heat transfer coefficient, W. $\mathrm{m}^{-2} \mathrm{~K}^{-1}$

I intensity, A

$j \quad$ imaginary number such that $j^{2}=-1$

$k$ thermal conductivity, W. $\mathrm{m}^{-1} \mathrm{~K}^{-1}$

L length, $m$

$\dot{m} \quad$ mass flowrate, $\mathrm{kg} \mathrm{s}^{-1}$

$\mathrm{N} \quad$ number of tubes

$\mathrm{Nu} \quad$ Nusselt number $\mathrm{Nu}=h D_{\mathrm{h}} / \mathrm{k}$

P heat flowrate, $\mathrm{W}$

Pr Prandtl number $\operatorname{Pr}=\mu c_{p} / k$

$\dot{q} \quad$ heat generation by unit of volume, W. $\mathrm{m}^{-3}$

Re Reynolds number $\operatorname{Re}=\rho \cup D_{\mathrm{h}} / \mu$

S surface, $\mathrm{m}^{2}$

$\mathrm{T}$ temperature, $\mathrm{K}$

th thickness, $\mathrm{m}$

\section{Introduction}

Compact brazed aluminium heat exchangers are essential components of refrigerating machines. They are composed of flat tubes on the refrigerant side and louver fins on the air side. The flat tubes are inserted in a header and the heat exchanger is designed for parallel flow. These kinds of heat exchangers are widely used in air-conditioning, due to their higher heat transfer coefficients and their charge reduction compared to conventional heat exchangers. Evaporators, contrary to condensers, are supplied with a two-phase fluid. The phases are unevenly distributed in the channels. According to Mueller and Chiou (1988), and Kitto Jr. and Robertson (1989), the maldistribution in heat exchangers is caused by:

- mechanical design, such as header and channel design, and manufacturing tolerance,

- self-induced maldistribution due to heat transfer,

- difficulties to distribute two-phase flow because of phase separation and flow instability,

- formation of fouling and corrosion.

According to Kulkarni et al. (2004), a bad distribution may result in a performance reduction of up to $20 \%$. Indeed, the presence of little liquid in a channel can promote a dry-out phenomenon, which will reduce drastically the heat transfer performance.

The investigation of maldistribution requires a complex experimental facility, especially if quantitative information has to be obtained. Moreover, most of the available measurement methods are invasive and may alter the measured values. Some authors (Webb and Chung, 2005) underlined that time, $s$

voltage, $\mathrm{V}$

volume, $\mathrm{m}^{3}$

width, $m$

quality

minimisation criterion

reduced temperature, $\mathrm{K}$

dynamic viscosity, Pa.s

density, kg. $\mathrm{m}^{-3}$

phase delay, rad

angular pulsation $\omega=2 \pi f$, $\operatorname{rad~s}^{-1}$

\section{Subscripts}

alt alternating

c continuous part

ch channel

f fluid

in inlet

meas measured

$\mathrm{t}$ tube

w wall

$\omega$ angular excitation frequency the investigation of geometrical parameters influence on distribution should imply the use of a non-invasive measuring method.

Microchannel heat exchangers are composed of many parallel tubes with reduced sections. These exchangers are already widely used and have the advantage of reducing refrigerant charge, system size, refrigerant pressure drops, air pressure drops, and of enhancing heat transfer. However, in these exchangers, flow distribution is operated by cylindrical headers distributing a large number of parallel channels (Hrnjak, 2002). The efficiency of these heat exchangers, and especially of evaporators, highly depends on the uniformity of the two-phase distribution through the channels.

The most common method to characterise distribution, consists in measuring quality and mass flowrate over the whole heat exchangers. Here, the authors are interested in investigating a new method.

\subsection{Direct methods}

Several experimental studies have been carried out to characterise two-phase flow distribution in microchannel heat exchangers in order to provide essential information for a better design. Bernoux (2000), and later Ahmad et al. (2009), used a heavily instrumented experimental loop. It was composed of eight coriolis flow meters and eight differential pressure transducers to study the distribution of two-phase R-113 and HFE-7100 in eight channels. This configuration requires a modified heat exchanger without outlet header and is only suited for a few channels. The same protocol has also been used by Poggi et al. (2009) for two-phase HFE-7100. 
Kim and Sin (2006) used a heat exchanger divided in two parts to insert a derivation system. With this modification, distribution of two-phase fluid can be evaluated by measuring flowrate and quality at each channel, but only one by one. Hwang et al. (2007) used a similar system to characterise the distribution of two-phase R-410A. With this configuration, a heat exchanger with an outlet header was used, but this system requires an accurate pressure drop measurement to balance the influence of sampling.

\subsection{Indirect methods}

Other methods have been developed for flow distribution studies. Hrnjak (2004a, b) presented two easy to implement non-invasive methods. The first one consists in measuring the temperature distribution of the evaporator outlet surface by IR thermography. The second method consists in observing the distribution of the frost formation at the evaporator surface. Both methods provide only qualitative information about distribution.

For liquid distribution, O'Halloran et al. (2004) used Particle Image Velocimetry to study the distribution. They developed a heat exchanger consisting of transparent headers and tubes. This method provides good results, but is not suited to twophase flow.

Distribution can also be evaluated by measuring the airflow temperature through an evaporator. Using this approach, Shi et al. (2011) studied the influence of geometry on distribution of R-134a. They developed a two-pass evaporator with a set of perforated plates to insert in the inlet and outlet headers. The plates were designed to generate a distribution modification by means of series of holes. Air side temperature was measured with thermocouples and authors relied on these data to support their observations. In this study, temperature distribution became a global performance indicator and not correlated to the refrigerant distribution.

IR thermography was used by Sa et al. (2003) to provide information on two-phase distribution. Transient measurements were performed with various exchanger configurations. Knowledge of transient temperature distribution, together with quantitative data such as heat transfer rate and pressure drop, are used to select the best configuration.

Another approach is to use IR thermography with a steadystate technique. This non-invasive measurement method delivers rapid temperature measurements and qualitative information about the distribution. If local heat flux and fluid temperature are exactly known, a mapping of the heat transfer coefficients is then possible and could provide more information. Unfortunately, there is no simple way to measure local internal temperatures of the fluid.

The present paper focuses on the development of an innovative method designed to measure the efficiency of a heat exchanger. The overall heat transfer coefficients measurement allows qualifying the efficiency of the distribution. This method is based on an IR thermography measurement of the flat tubes surface temperature under a periodic heat flux delivered by Joule effect. Measurements are coupled to a mathematical model to compute the heat transfer coefficient. The method was first applied and validated on a round tube by Leblay et al. (2013). Considering the satisfying results, it was then applied on a multiport flat tube and on a complete heat exchanger to evaluate the heat transfer distribution.

\section{Measurement principle}

The method was initially developed to determine local heat transfer coefficients on the inner wall of a pipe, with a noninvasive, fluid independent method. It was first applied in laminar and turbulent flow for a single multiport flat tube. It was then applied on a heat exchanger composed of seven multiport flat tubes.

The measurement system consists of an IR camera, a modulated electrical heat source, software to control the camera as well as visualising and recording the IR images, an ammeter, and a voltmeter. Measurements of heat flux and temperature amplitude were used as input variables for the model to calculate the heat transfer coefficients.

A sinusoidal wave DC generator electrically heated the connected tubes and the output voltage was modulated at low frequency $(f=0.05 \mathrm{~Hz}$ in this study). Since the tube acts as a pure resistance, the current wave has the same frequency and phase as the voltage. Their expressions are given in Eq. (1).

$U=U_{\text {mean }}+U_{\text {alt }} \cos (\omega t)$
$I=I_{\text {mean }}+I_{\text {alt }} \cos (\omega t)$

The power dissipated by Joule effect in the tubes is equal to the product UI and therefore has three components: a continuous one, one at the excitation frequency $f$ and one at the frequency $2 f$. It is given in Eq. (2):

$P=P_{c}+P_{\omega} \cos (\omega t)+P_{2 \omega} \cos (2 \omega t)$

and 3:

$P_{c}=U_{\text {mean }} I_{\text {mean }}+\frac{U_{\text {alt }} I_{\text {alt }}}{2}$
$P_{\omega}=U_{\text {mean }} I_{\text {alt }}+U_{\text {mean }} I_{\text {alt }}$
$P_{2 \omega}=\frac{U_{\text {alt }} I_{\text {alt }}}{2}$

The measurement of the distribution can be decomposed in three stages. Firstly, an experimental facility was developed to apply and modulate the heat flux, and to measure the evolution of the wall temperature. Secondly, a model was developed to link the heat transfer coefficient to the measured data. Thirdly, heat transfer coefficients were compared in terms of Nusselt ratio to analyse the quality of the distribution.

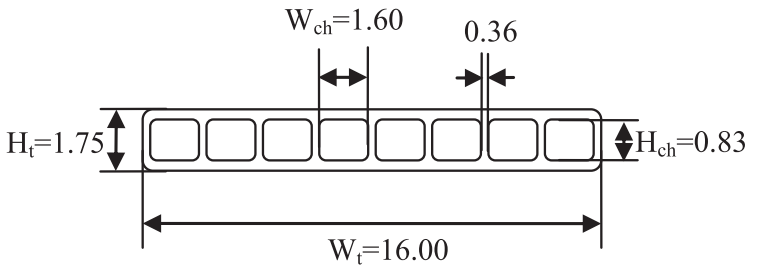

Fig. 1 - Cross-sectional view of the multiport flat tube (unit: $\mathbf{m m})$. 


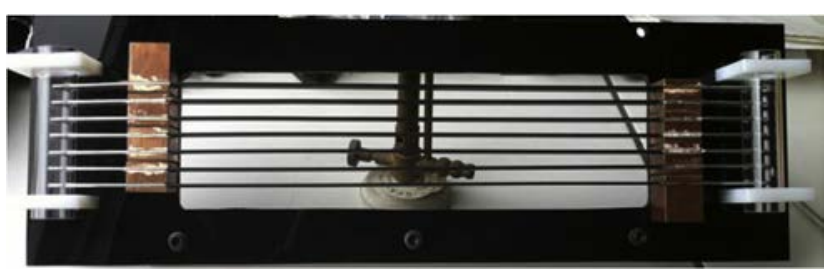

Fig. 2 - Test section.

\subsection{Experimental facility}

Measurement sessions are conducted both on a multiport flat tube and on a heat exchanger. The tube is made of aluminium and its geometry is presented in Fig. 1. It is supplied with water.

The exchanger, presented in Fig. 2, is composed of two headers and seven multiport flat tubes with two-phase air/ water flow. Both headers are acrylic round tubes of $2.1 \mathrm{~cm}$ diameter. They are transparent to allow flow pattern visualisation. The tubes are connected to the vertical headers with a pitch of $1 \mathrm{~cm}$ and inserted with an intrusion depth of $1 \mathrm{~cm}$, as presented in Fig. 3.

The flat tube and the heat exchanger are electrically heated through a power supply that provides a periodic heating by Joule effect. A tube length of $30 \mathrm{~cm}$, located between electrodes connected to the power supply with copper cables, is heated at a frequency of $0.05 \mathrm{~Hz}$. To supply every tube of the exchanger with the same power, tubes are connected in series with copper electrodes, as presented in Fig. 4.

The IR camera (Titanium Cedip) measures the temperature on the external surface of the tubes at a $2 \mathrm{~Hz}$ frequency. This enables to capture 400 points in $200 \mathrm{~s}$ and thus 10 periods. Every tube external surface is painted in black so as to increase and homogenise the emissivity. The area observed by the camera, presented in Fig. 5, is about $20 \mathrm{~cm}$ long and is located in the middle of the area heated by Joule effect. The areas considered for calculation are part of each tube, about $1.2 \mathrm{~cm}$ wide and $2.4 \mathrm{~cm}$ high. Each coloured rectangle in Fig. 5 corresponds to a flat tube. To measure the temperature evolution of the complete exchanger, the IR camera is inclined with an angle of $45^{\circ}$. An example of temperature evolution of the tubes over time is presented in Fig. 6. The peak-to-peak amplitude of the oscillations varies from a few tenths of a degree to few degrees of magnitude, depending on the experimental conditions.

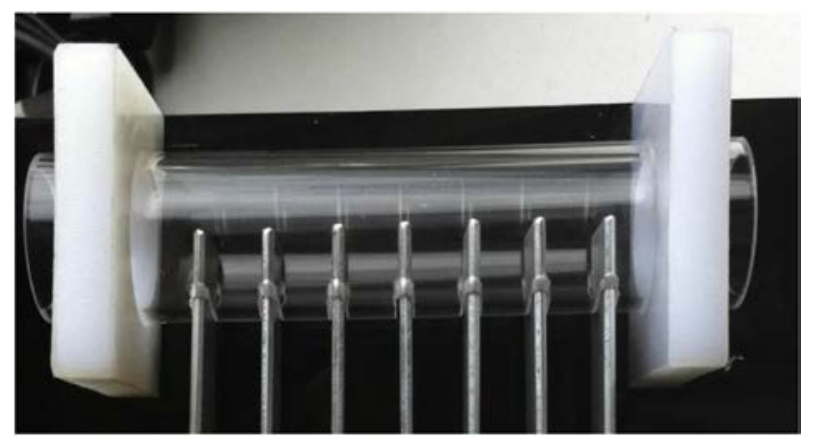

Fig. 3 - Connection between header and tubes.

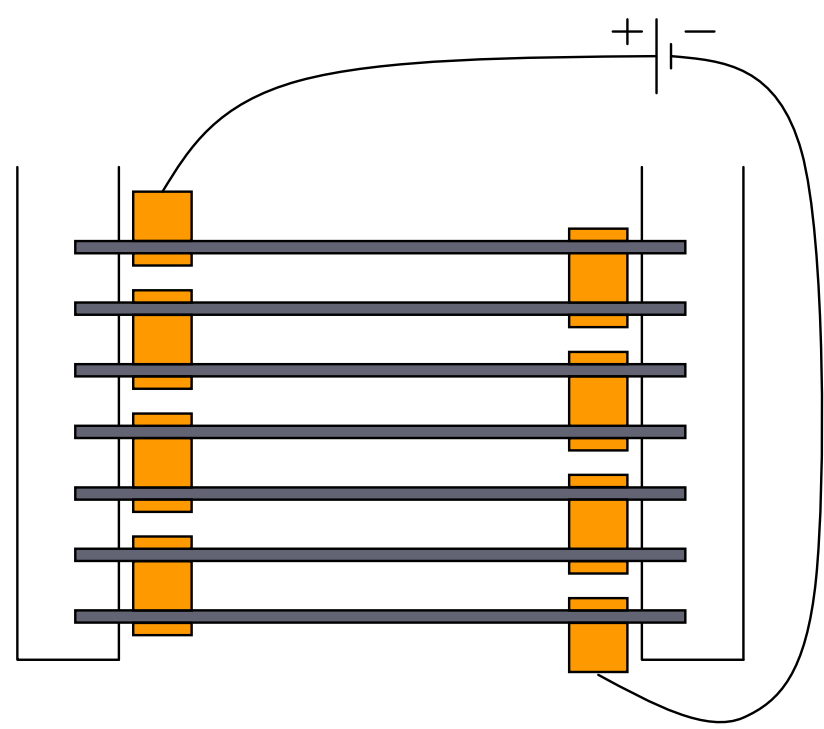

Fig. 4 - Electrical assembly.

The same hydraulic circuit, presented in Fig. 7, is used for the flat tube and for the exchanger. For the flat tube, the water flowrate is controlled by a valve in order to reach Reynolds numbers ranging from 800 to 10000 . For the exchanger, air and water are used as working fluids. The two fluids are mixed through a static mixer to homogenise the flow. Both fluids flowrates are measured by flowmeters and valves control water and air flowrate. Total inlet mass flux and quality of air-water range from $29 \mathrm{~kg} \mathrm{~m}^{-2} \mathrm{~s}^{-1}$ to $116 \mathrm{~kg} \mathrm{~m}^{-2} \mathrm{~s}^{-1}$, and $10 \%-70 \%$, respectively. A thermocouple, located at the outlet of the test section, measures the water temperature during experiments in order to check that it remained constant during the test. The tank temperature is controlled using a thermocouple connected to the data logger.

\subsection{Heat transfer model}

The developed heat transfer model considers the flat tube as a wall, as presented in Fig. 8. Since there is a symmetry plane induced by the geometry, only half of the flat tube is considered. The relation between the periodic heating energy and the temperature oscillations of the external wall is given by the heat conduction equation in the wall and by the boundary conditions. These conditions are a convective heat flux imposed on the inner surface of the tube and an adiabatic condition on the outer surface. External radiative and convective heat transfer coefficients $\left(h_{\mathrm{rd}} \approx 6 \mathrm{~W} \mathrm{~m}^{-2} \mathrm{~K}^{-1}\right.$ and $h_{\mathrm{cv}} \approx 4 \mathrm{~W} \mathrm{~m}^{-2} \mathrm{~K}^{-1}$ ) represent less than $1 \%$ of the internal heat transfer coefficient in the worst case. Heat losses by external convection and radiation will therefore be neglected. To take into account the influence of the fins formed by small-channel separations, two different surfaces were added to the model. Surfaces $S_{1}$ and $S_{2}$ were considered respectively for conduction and for convection.

Considering the low heat flux provided by the power supply, between $5 \mathrm{~W}$ and $35 \mathrm{~W}$, a second assumption is a constant fluid temperature as boundary condition. The thermodynamic properties of the material and the convection coefficient are 


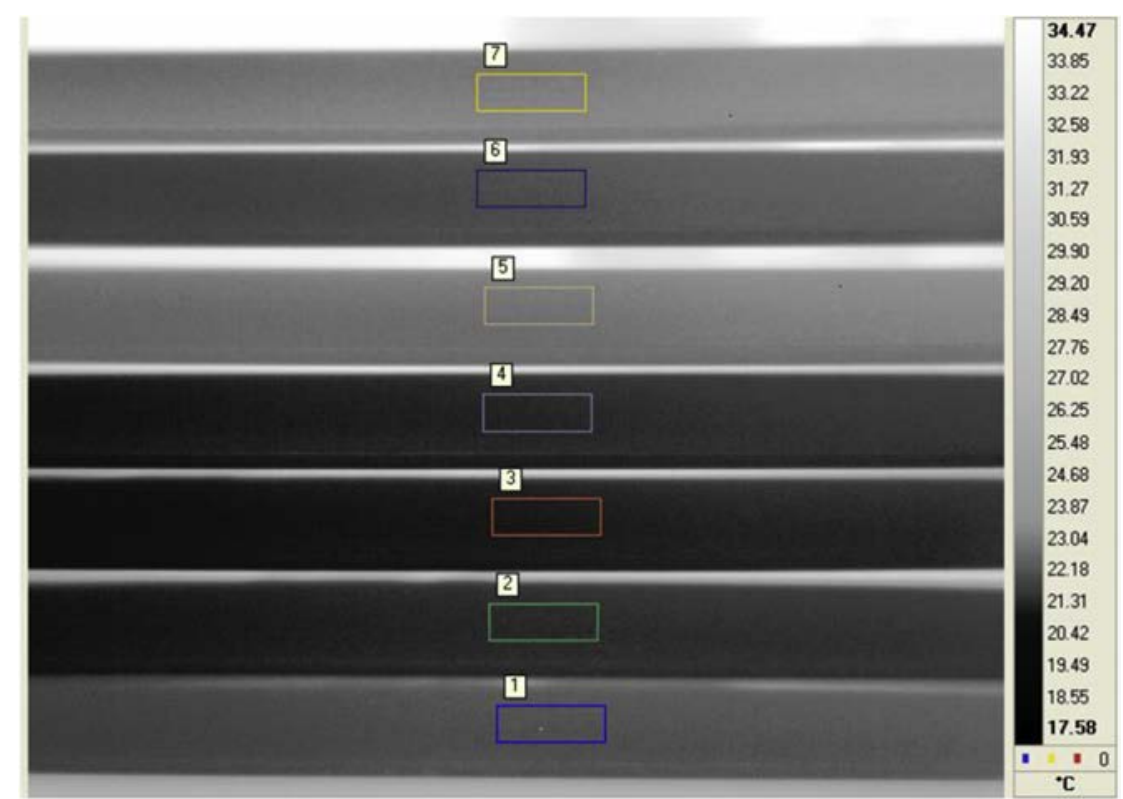

Fig. 5 - Areas considered for IR thermography measurement.

assumed to be independent of the temperature. Finally, heat transfers in any other direction than the $\mathrm{x}$-axis are neglected and the model will be developed in one dimension.

The system to solve, composed of the energy equation and boundary conditions, is given in Eq. (4).

$$
\left\{\begin{array}{l}
\frac{\partial^{2} T_{\mathrm{w}(x, t)}}{\partial x^{2}}-\frac{1}{a} \frac{\partial T_{\mathrm{w}(x, t)}}{\partial t}=-\frac{\dot{q}_{(t)}}{k} \\
x=t h-\left.k S_{1} \frac{\partial T_{\mathrm{w}(x, t)}}{\partial x}\right|_{x=t h}=h S_{2}\left(T_{\mathrm{w}(t h, t)}-T_{\mathrm{f}, \mathrm{in}}\right) \\
x=0-\left.k \frac{\partial T_{\mathrm{w}(x, t)}}{\partial x}\right|_{x=0}=0
\end{array}\right.
$$

with $\dot{q}_{(t)}$ the heat generation divided by the volume of aluminium of the tube and the thickness of the wall (cf. Fig. 8). Temperature, similarly to power, has three components: a continuous one, one at the excitation frequency, and one at a frequency twice the excitation frequency. By defining the difference of temperature $\theta_{\mathrm{w}(x, \mathrm{t})}$ by:

$\theta_{\mathrm{w}(x, t)}=\left(\mathrm{T}_{\mathrm{w}(\mathrm{x}, \mathrm{t})}-\mathrm{T}_{\mathrm{f}, \mathrm{in}}\right)$

and assuming a periodic established state, we obtain:

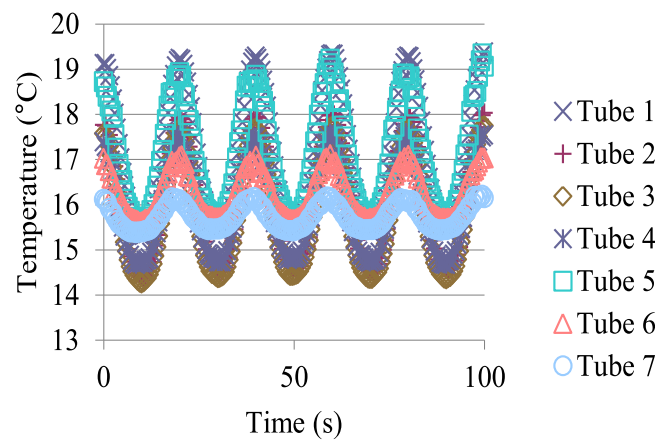

Fig. 6 - Temperature evolution of tubes over time. $\theta_{\mathrm{w}(\mathrm{x}, \mathrm{t})}=\theta_{\mathrm{w}, \mathrm{c}(\mathrm{x})}+\theta_{\mathrm{w}, \omega(\mathrm{x})} \exp \left(\mathrm{j}\left(\omega \mathrm{t}+\varphi_{\omega}\right)\right)+\theta_{\mathrm{w}, 2 \omega(\mathrm{x})} \exp \left(\mathrm{j}\left(2 \omega t+\varphi_{2 \omega}\right)\right)$

and:

$\dot{q}_{(t)}=\dot{q}_{c}+\dot{q}_{\omega} \exp (j \omega t)+\dot{q}_{2 \omega} \exp (j 2 \omega t)$

where $\varphi$ is the phase shift between the temperature and the heat source. The system at the excitation frequency becomes:

$\left\{\begin{array}{l}\frac{\partial^{2} \theta_{\mathrm{w}, \omega(x)}}{\partial x^{2}} \exp \left(j\left(\omega t+\varphi_{\omega}\right)\right)-\frac{j \omega}{a} \theta_{\mathrm{w}, \omega(x)} \exp \left(j\left(\omega t+\varphi_{\omega}\right)\right)=-\frac{\dot{q}_{\omega}}{k} \exp (j \omega t) \\ x=t h-\left.k S_{1} \frac{\partial \theta_{\mathrm{w}, \omega(x)}}{\partial x}\right|_{x=t h} \exp \left(j\left(\omega t+\varphi_{\omega}\right)\right)=h S_{2} \theta_{\mathrm{w}, \omega(\mathrm{th})} \exp \left(j\left(\omega t+\varphi_{\omega}\right)\right) \\ x=0-\left.k \frac{\partial \theta_{\mathrm{w}, \omega(x)}}{\partial x}\right|_{x=0} \exp \left(j\left(\omega t+\varphi_{\omega}\right)\right)=0\end{array}\right.$

The energy equation becomes:

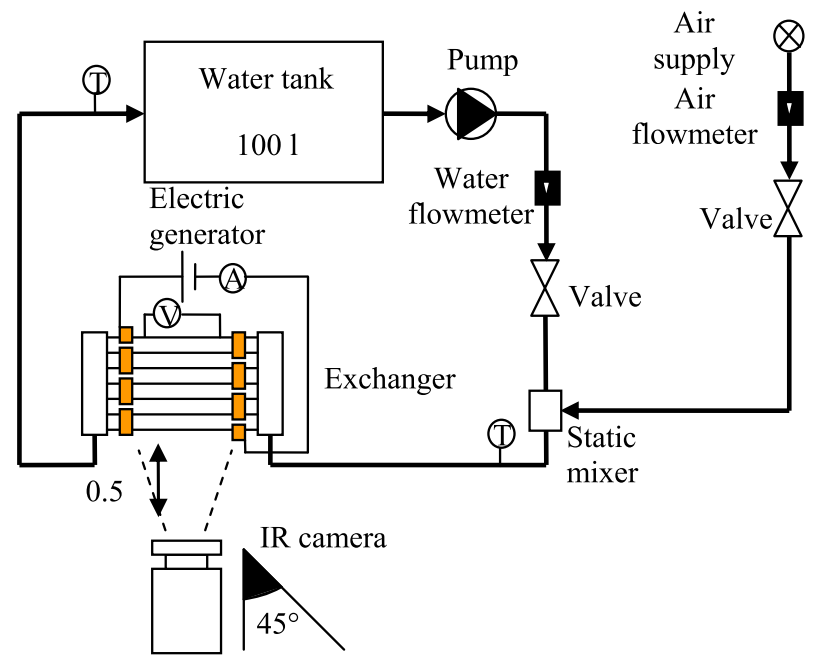

Fig. 7 - Hydraulic circuit. 


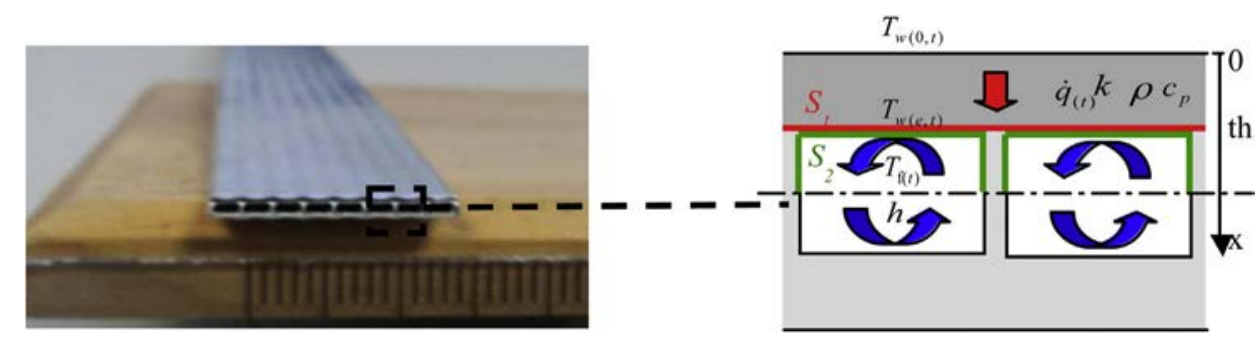

Fig. 8 - Representation of the multiport flat tube and related quantities.

$\frac{\partial^{2} \theta_{\mathrm{w}, \omega(x)}}{\partial x^{2}} \exp \left(j \varphi_{\omega}\right)-m_{\omega}^{2} \theta_{\mathrm{w}, \omega(x)} \exp \left(j \varphi_{\omega}\right)=-\frac{\dot{q}_{\omega}}{k}$

with:

$m_{\omega}=\sqrt{\frac{j \omega}{a}}$

The solution of the equation of energy conservation being the amount of the particular equation plus the general equation, we have:

$\theta_{\mathrm{w}, \omega(x)} \exp \left(j \varphi_{\omega}\right)=-\frac{\dot{q}_{\omega}}{m_{\omega}^{2} k}+A_{\omega} \cosh \left(m_{\omega} x\right)+B_{\omega} \sinh \left(m_{\omega} x\right)$

With the boundary condition for $x=0$, we obtain:

$B_{\omega}=0$

Finally, with the boundary condition for $x=$ th, we obtain:

$$
A_{\omega}=\frac{-\frac{\dot{q}_{\omega}}{m_{\omega}^{2} k}}{\frac{m_{\omega} k}{h} \frac{S_{1}}{S_{2}} \sinh \left(m_{\omega} t h\right)+\cosh \left(m_{\omega} t h\right)}
$$

The resolution of the system provides the expression of temperature variation in the wall $\theta_{\omega(x)} \exp \left(j \phi_{\omega}\right)$, given in Eq. (14).

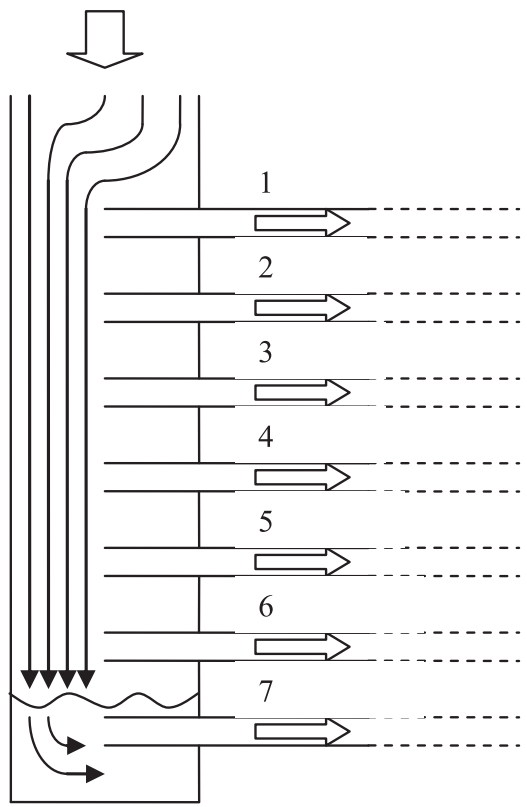

Fig. 9 - Numbering of the tubes along the header. $\theta_{\mathrm{w}, \omega(\mathrm{x})} \exp \left(j \varphi_{\omega}\right)=\frac{\dot{q}_{\omega}}{m_{\omega}^{2} k}\left(1-\frac{\cosh \left(m_{\omega} \mathrm{x}\right)}{\frac{\mathrm{km}_{\omega}}{\mathrm{h}} \frac{\mathrm{S}_{1}}{\mathrm{~S}_{2}} \sinh \left(m_{\omega} \mathrm{th}\right)+\cosh \left(m_{\omega} \mathrm{th}\right)}\right)$

The same resolution was applied to the system at twice the excitation frequency to obtain the expression of $\theta_{\mathrm{w}, \omega(\mathrm{x})} \exp \left(\mathrm{j} \phi_{\omega}\right)$ given by:

$\theta_{\mathrm{w}, 2 \omega(\mathrm{x})} \exp \left(j \varphi_{2 \omega}\right)=\frac{\dot{q}_{2 \omega}}{m_{2 \omega}^{2} k}\left(1-\frac{\cosh \left(m_{2 \omega} \mathrm{x}\right)}{\frac{\mathrm{km}_{2 \omega}}{\mathrm{h}} \frac{S_{1}}{S_{2}} \sinh \left(m_{2 \omega} \mathrm{th}\right)+\cosh \left(m_{2 \omega} \text { th }\right)}\right)$

with:

$m_{2 \omega}=\sqrt{\frac{2 j \omega}{a}}$

For the flat tube, the heat flux ranged from $30 \mathrm{~W}$ to $80 \mathrm{~W}$. Considering Eqs. (5)-(7) with:

$\mathrm{T}_{\mathrm{f}(\mathrm{t})}=\theta_{\mathrm{f}, \mathrm{c}}+\theta_{\mathrm{f}, \omega} \exp \left(\mathrm{j}\left(\omega \mathrm{t}+\varphi_{\omega}\right)\right)+\theta_{\mathrm{f}, 2 \omega} \exp \left(\mathrm{j}\left(2 \omega t+\varphi_{2 \omega}\right)\right)$

and the energy balance giving:

$\theta_{\mathrm{f}, \omega} \exp \left(j \varphi_{\omega}\right)=\frac{\dot{q}_{\omega} \mathrm{V}}{2 \dot{m}_{\mathrm{f}} c_{p, \mathrm{f}}}$

the expression of $\theta_{\mathrm{w}, \omega(\mathrm{x})} \exp \left(j \phi_{\omega}\right)$, is given by:

$\theta_{\mathrm{w}, \omega(x)} \exp \left(j \varphi_{\omega}\right)=\frac{\dot{q}_{\omega}}{m_{\omega}^{2} k}\left(1-\frac{\left(1-\frac{m_{\omega}^{2} k V}{2 m_{\mathrm{f}} c_{p, \mathrm{f}}} \cosh \left(m_{\omega} x\right)\right)}{\frac{k m_{\omega}}{h} \frac{S_{1}}{S_{2}} \sinh \left(m_{\omega} t h\right)+\cosh \left(m_{\omega} t h\right)}\right)$

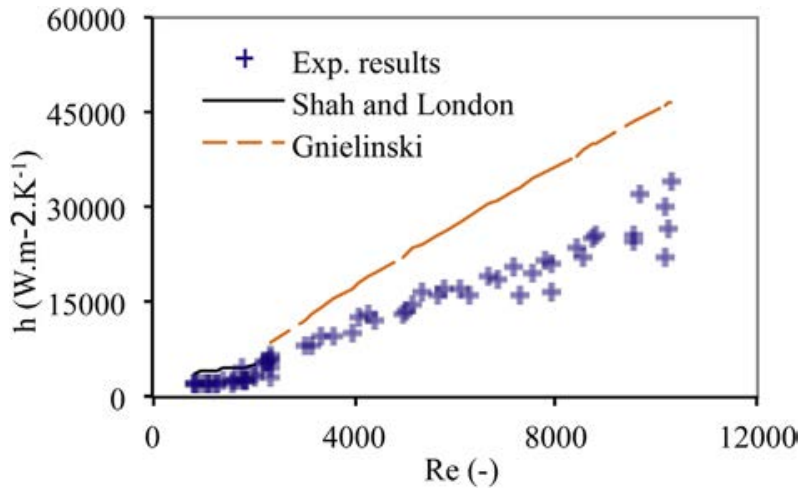

Fig. 10 - Comparison of heat transfer coefficients obtained experimentally and from correlations as a function of the Reynolds number. 


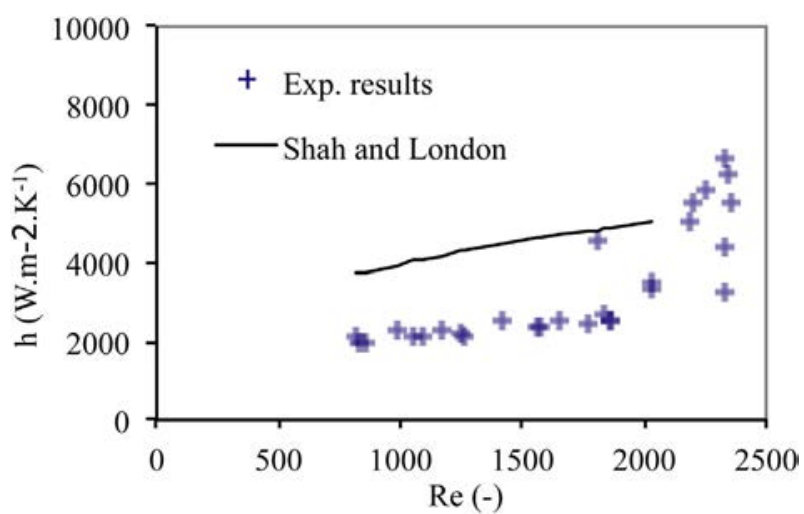

Fig. 11 - Comparison of heat transfer coefficients obtained experimentally and from correlations as a function of the Reynolds number for laminar flow.

Knowing that:

$\theta_{(x)}=\left|\theta_{\omega(x)} \exp \left(j \varphi_{\omega}\right)+\theta_{2 \omega(x)} \exp \left(j \varphi_{2 \omega}\right)\right|$

an evaluation of the heat transfer value is finally obtained by minimizing $\varepsilon$ such that given in Eq. (21).

$\varepsilon=\left|\theta_{(0) \text { meas }}-\theta_{(0)}\right|$

where $\theta_{(0) \text { meas }}$ is the experimental amplitude of the temperature oscillations. The convective heat transfer coefficient $h$ can be determined with the properties of the tube material $c_{p}$, $k, \rho$, the excitation frequency $\omega$, the power densities $\dot{q}_{\omega}$ and $\dot{q}_{2 \omega}$, and the amplitude of the measured temperature $\theta_{(0) \text { meas }}$.

The algorithm developed to deduce heat transfer coefficient from temperature measurement was detailed in Leblay et al. (2013). The three main steps are, firstly, the data analysis of the results to compensate for temperature increase over time, secondly, the temperature amplitude calculation, and, thirdly, the iterative calculation of the heat transfer coefficient.

\section{Table 1 - Uncertainty propagation.}

\begin{tabular}{|c|c|c|}
\hline Variable \pm uncertainty & Partial derivative & $\begin{array}{l}\% \text { of the } \\
\text { uncertainty }\end{array}$ \\
\hline$k=237 \pm 10\left[\mathrm{~W} \cdot \mathrm{m}^{-1} \mathrm{~K}^{-1}\right]$ & $\partial h / \partial k=-0.09$ & $0.00 \%$ \\
\hline$c_{p}=910 \pm 10\left[\mathrm{~J} \mathrm{~kg}^{-1} \mathrm{~K}^{-1}\right]$ & $\partial h / \partial c_{p}=-0.03$ & $0.00 \%$ \\
\hline$\rho=2700 \pm 100\left[\mathrm{~kg} \cdot \mathrm{m}^{-3}\right]$ & $\partial h / \partial \rho=-0.01$ & $0.00 \%$ \\
\hline$L=0.2920 \pm 0.0005[\mathrm{~m}]$ & $\partial h / \partial L=-14649$ & $0.02 \%$ \\
\hline th $=0.00046 \pm 0.00005[\mathrm{~m}]$ & $\partial h / \partial t h=9298706$ & $69.17 \%$ \\
\hline $\mathrm{W}_{\mathrm{t}}=0.0160 \pm 0.0005[\mathrm{~m}]$ & $\partial h / \partial W_{t}=264893$ & $5.61 \%$ \\
\hline$H_{\mathrm{ch}}=0.00083 \pm 0.00005[\mathrm{~m}]$ & $\partial h / \partial H_{c h}=-350952$ & $0.10 \%$ \\
\hline $\mathrm{W}_{\mathrm{ch}}=0.00159 \pm 0.00005[\mathrm{~m}]$ & $\partial \mathrm{h} / \partial \mathrm{W}_{\mathrm{ch}}=-1831055$ & $2.68 \%$ \\
\hline$U_{\min }=0.084 \pm 0.005[\mathrm{~V}]$ & $\partial \mathrm{h} / \partial U_{\min }=-17883$ & $2.56 \%$ \\
\hline$U_{\max }=0.174 \pm 0.005[\mathrm{~V}]$ & $\partial h / \partial U_{\max }=33142$ & $8.79 \%$ \\
\hline$I_{\min }=120 \pm 5[\mathrm{~A}]$ & $\partial h / \partial I_{\min }=-13$ & $1.25 \%$ \\
\hline$I_{\max }=249 \pm 5[\mathrm{~A}]$ & $\partial h / \partial I_{\max }=23$ & $4.30 \%$ \\
\hline$f=0.050 \pm 0.001[\mathrm{~Hz}]$ & $\partial h / \partial f=-549$ & $0.00 \%$ \\
\hline$\theta=0.65 \pm 0.02[\mathrm{~K}]$ & $\partial h / \partial \theta=-6561$ & $5.51 \%$ \\
\hline $\begin{array}{c}h=4234.7 \pm 559.0 \\
{\left[W \cdot \mathrm{m}^{-2} \mathrm{~K}^{-1}\right]}\end{array}$ & & $100.00 \%$ \\
\hline
\end{tabular}

\subsection{Data processing}

The experiments for the flat tube were conducted for a large range of water flowrates. The results obtained experimentally were compared with values obtained from the correlation of Gnielinski (1976). The thermodynamic properties were considered at mean temperature, such that:

$\mathrm{T}_{\text {mean }}=\frac{\mathrm{T}_{\text {in }}+\mathrm{T}_{\text {out }}}{2}$

The correlation of Gnielinski (1976), adapted to transitional and turbulent flows, is given by:

$\mathrm{Nu}=\frac{f / 8(\operatorname{Re}-1000) \operatorname{Pr}}{1+12.7 \sqrt{f / 8}\left(\operatorname{Pr}^{2 / 3}-1\right)}\left(1+\left(D_{\mathrm{h}} / \mathrm{L}\right)^{2 / 3}\right)\left(\operatorname{Pr} / \operatorname{Pr}_{\mathrm{w}}\right)^{0.11}$

where $L$ is the establishment length of the flow in the tube before the measurement point, $\mathrm{Pr}_{\mathrm{w}}$ is the value of the Prandtl number at wall temperature, and $f$ is the Darcy friction factor defined by:

$f=\frac{0.3164}{\operatorname{Re}^{1 / 4}}$

This correlation is valid for $1.5<\operatorname{Pr}<500,2300<\operatorname{Re}<10^{6}$, and $0<D_{\mathrm{h}} / \mathrm{L}<1$.

For laminar flow, the correlation of Shah and London (1978) was used:

$\mathrm{Nu}=1,953\left(\operatorname{Re} \operatorname{Pr} D_{\mathrm{h}} / L\right)^{1 / 3}$

This correlation is valid for $\operatorname{Re} \operatorname{Pr} D_{h} / L \geq 33.3$. It was developed for non-established flow and uniform heat flux.

Generally, in distribution studies, the flowrate in each channel is evaluated in terms of liquid and gas flow ratio in each channel. The flow ratio $\dot{m}_{i}^{*}$ is the ratio of the flowrate of the phase considered $\dot{m}_{\mathrm{i}}$ inside the tube number $i$ over the mean flowrate of this phase. It is given in Eq. (26):

$\dot{m}_{i}^{*}=\frac{\dot{m}_{i}}{\sum_{j=1}^{N} \dot{m}_{j} / N}$

The discrepancy between the flowrates in each channel is representative of the distribution in the heat exchanger. Similarly, to compare the distribution of heat transfer coefficients obtained for various flowrates and qualities, results are presented here in terms of Nusselt ratio. The Nusselt ratio $\mathrm{Nu}_{\mathrm{i}}^{*}$ of the tube number $\mathrm{i}$ is the ratio of the Nusselt number measured $\mathrm{Nu}_{\mathrm{i}}$ on the tube $i$ over the mean Nusselt number calculated for all the tubes (Eq. (27)).

$\mathrm{Nu}_{\mathrm{i}}^{*}=\frac{\mathrm{Nu}_{\mathrm{i}}}{\sum_{j=1}^{\mathrm{N}} \mathrm{Nu}_{\mathrm{j}} / \mathrm{N}}$

We have a relative comparison of the heat transfer obtained along the header, with a value of 1 for a homogeneous distribution. The channel numbering is presented in Fig. 9.

\section{Experimental results}

\subsection{Multiport flat tube}

The results concerning the multiport flat tube are presented in Fig. 10. The results obtained in laminar flow are presented in 


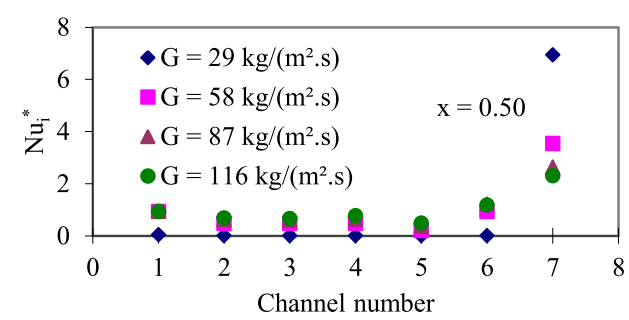

a)

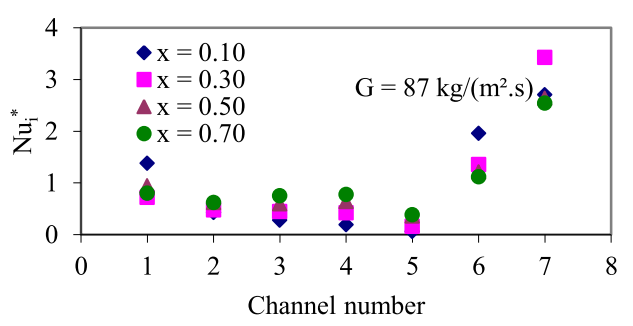

b)

Fig. 12 - Effect of mass flux on Nusselt ratio (a) and Nusselt number (b) distribution along the header.

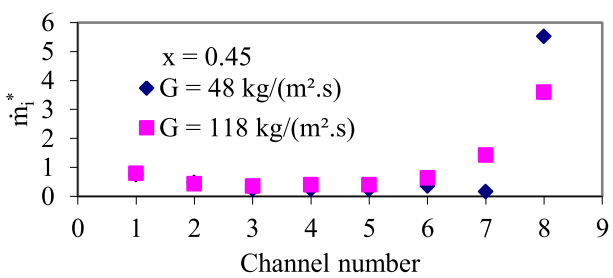

a)

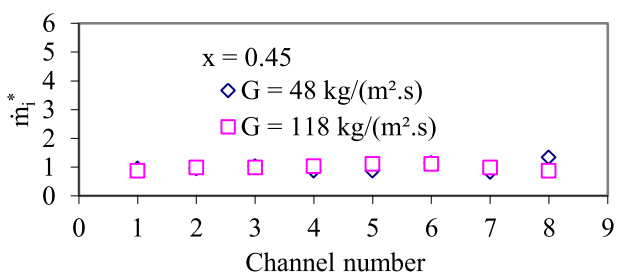

b)

Fig. 13 - Effect of mass flux on flow distribution of liquid (a) and gas (b) along the header.

Fig. 11. Regarding the general trend, it appears that the flow regimes are consistent with theory. In particular, the transition from laminar to turbulent occurs for a value of the Reynolds number between 2000 and 2500 . A commonly accepted value for the appearance of turbulence for round tubes is 2300 .

However, the experimental results appear lower than those obtained from the correlations. These differences may be related to the geometry. Indeed, correlations were established for round tubes. Small-channels have a rectangular section. Furthermore, the variations observed for high Reynolds numbers highlight the need to increase the heat flux provided to increase the accuracy. Other sources of error considered are the longitudinal conduction and conduction by power cables. Additional tests should be carried out to check this assumption.

An uncertainty propagation was carried out in order to investigate the influence of all the parameters required to evaluate the heat transfer coefficient. A summary of the influence of each parameter on the heat transfer coefficient uncertainty is presented in Table 1 . It can be seen that the measurement of wall thickness and heat flux has a major influence on the heat transfer coefficient evaluation.

The thermophysical properties of the tube material have little influence. This is an interesting result, as the material properties are not always accurately known.

\subsection{Exchanger}

The effect of mass flow on heat transfer distribution for a vertical downward header is presented in Fig. 12. It appears that, independently of the value of mass flux, greater heat transfer characterises the seventh channel. Heat transfer is almost evenly distributed for the tubes one to five. These results can be compared to the results from Poggi et al. (2009) (Fig. 13) for a similar vertical heat exchanger and similar operating conditions. The visualisation of the flow through the transparent header showed that liquid flow hitting the first tube is projected at the bottom of the header. Liquid accumulates at the bottom of the header, resulting in a major supply through the last tubes. The gas phase is evenly distributed.

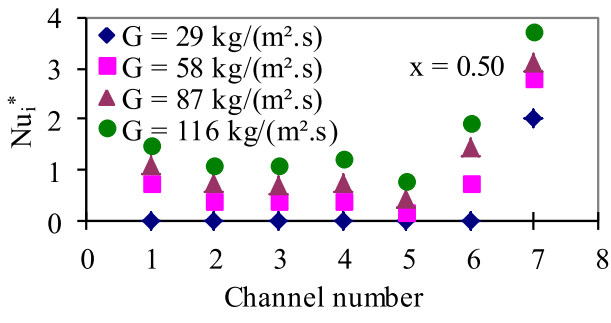

a)

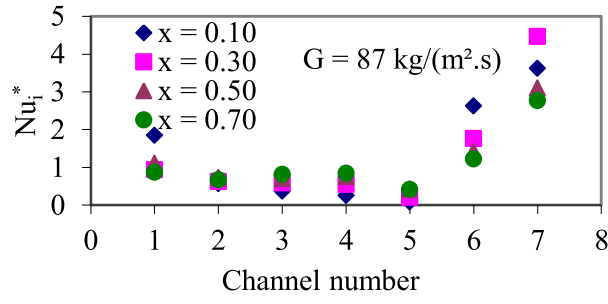

b)

Fig. 14 - Effect of quality on Nusselt ratio (a) and Nusselt number (b) distribution along the header. 


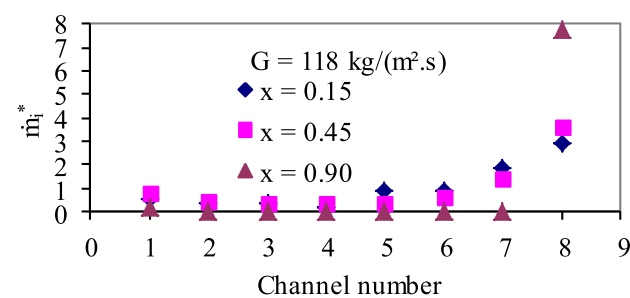

a)

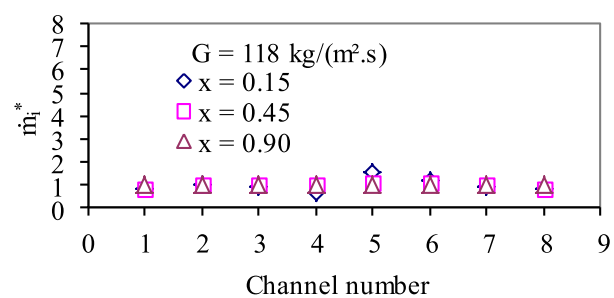

b)

Fig. 15 - Effect of quality on flow distribution of liquid (a) and gas (b) along the header.

Our results are consistent with the results of Poggi et al. (2009). Indeed, with a homogeneous gas distribution, heat transfers are mainly linked to liquid distribution.

The effect of quality on the distribution of heat transfer is presented in Fig. 14. It appears through the heat transfer coefficient measurements that, for a low quality $(x=0.1)$, the last tubes are oversupplied and the tubes 2 to 5 undersupplied. For an intermediate quality, the distribution is homogeneous for the first five tubes and sharply increases for the last two. Finally, for a high quality $(x=0.70)$, the distribution of heat transfer is homogeneous for the first four tubes, falling for the fifth and increasing for the last two. Results obtained by Poggi et al. (2009) on the influence of quality on distribution confirm these observations (Fig. 15).

\section{Conclusion}

A method has been developed to measure the convective heat transfer coefficient in a tube. This method is based on a modulated heat flux generated by Joule effect. The temperature amplitudes of the external wall of the tube are measured with an IR camera. Using these values as inputs of a simple analytical model, it is possible to quickly obtain a map of the local internal heat transfer coefficients. Using the same approach and a validated CFD model (Leblay, 2012), the method can also be extended to other shapes that are more complex than cylinders and plates. This flexibility makes it a suited tool to check series of elements.

However, measurements on a flat tube showed that the method provides values of heat transfer coefficients lower than those provided by correlations in this configuration. Additional tests are required to identify the cause of these differences. Still, the relative values of these heat transfer coefficients were consistent with the theoretical values. The transition from laminar to turbulent was thus properly measured.

This method has several advantages. It is a non-invasive measuring method which does not require the knowledge of the flowrate, temperature, or properties of the fluid. Moreover, heat fluxes delivered are low enough to avoid any major effect on the fluid flow. The use of IR thermography allowed us measuring heat transfer on several parallel flat tubes and to analyse the distribution of heat transfer.

Lock-in thermography can be used as an additional tool. In this case, thermograms could be used with a synchronous detection algorithm to obtain complete maps of amplitude and phase. These can then be correlated with heat transfer coefficient maps.

\section{Acknowledgements}

This work has been supported by the Cetim Foundation as part of the research project « Two Phase Flow Distribution in a Compact Heat Exchanger ».

\section{R E F E R E N C E S}

Ahmad, M., Berthoud, G., Mercier, P., 2009. General characteristics of two-phase flow distribution in a compact heat exchanger. Int. J. Heat. Mass Transf. 52 (1-2), 442-450.

Bernoux, P., 2000. Etude de la distribution d'un mélange liquidevapeur à l'entrée des échangeurs de chaleur. Université Henri Poincaré - Nancy I, p. 240. Ph.D. thesis.

Gnielinski, V., 1976. New equations for heat and mass-transfer in turbulent pipe and channel flow. Int. J. Chem. Eng. 16 (2), 359-368.

Hrnjak, P.S., 2002. Microchannel heat exchangers as a design option for charge reduction in $\mathrm{nh}_{3}$ and hc systems. Zero Leakage - Minim. Charge, 111-118.

Hrnjak, P.S., 2004a. Developing adiabatic two phase flow in headers - distribution issue in parallel flow microchannel heat exchangers. Heat. Transf. Eng. 25 (3), 61-68.

Hrnjak, P.S., 2004b. Flow distribution issues in parallel flow heat exchangers. ASHRAE Trans. 110, 301-306.

Hwang, Y., Jin, D.-H., Radermacher, R., 2007. Refrigerant distribution in minichannel evaporator manifolds. HVAC \& $\mathrm{R}$ Res. 13 (4), 543-555.

Kim, N.-H., Sin, T.-R., 2006. Two-phase flow distribution of airwater annular flow in a parallel flow heat exchanger. Int. J. Multiph. Flow. 32 (12), 1340-1353.

Kitto Jr., J.B., Robertson, J.M., 1989. Effects of maldistribution of flow on heat transfer equipment performance. Heat. Transf. Eng. 10 (1), 18-25.

Kulkarni, T., Bullard, C.W., Cho, K., 2004. Header design tradeoffs in microchannel evaporators. App. Therm. Eng. 24 (5-6), 759-776.

Leblay, P., 2012. Optimisation d'un évaporateur à mini-canaux par la maîtrise de la distribution en fluide frigorigène. Université Pierre et Marie Curie. Ph.D. thesis.

Leblay, P., Henry, J.-F., Caron, D., Leducq, D., Bontemps, A., Fournaison, L., 2013. IR thermography measurement of convective coefficients in a pipe with periodic excitation. Int. J. Therm. Sci. 74 (0), 183-189. 
Mueller, A.C., Chiou, J.P., 1988. Review of various types of flow maldistribution in heat exchangers. Heat. Transf. Eng. 9 (2), $36-50$.

O'Halloran, S.P., Hosni, M.H., Beck, B.T., Eckels, S.J., 2004. Three dimensional velocity measurements in an automotive-size evaporator using particle image velocimetry. In: Proceedings of the ASME Heat Transfer/ Fluids Engineering Summer Conference, HT/FED, 3, pp. 723-731.

Poggi, F., Macchi-Tejeda, H., Leducq, D., Maréchal, A., Bontemps, A., 2009. Experimental and numerical study of the distribution of a single-phase flow in a small channel heat exchanger. In: IIR 1st Workshop on Refrigerant Charge Reduction. Cemagref Antony, France.
Sa, Y.C., Jang, D.Y., Ko, C.S., Oh, S.K., Oh, S.Y., Chung, B.Y., 2003. Flow mal-distribution of flat tube evaporator. In: Proceedings of the 4th International Symposium on Heating, Ventilating and Air Conditioning, pp. 817-822.

Shah, R.K., London, A.L., 1978. Laminar Flow Forced Convection in Ducts: a Source Book for Compact Heat Exchanger Analytical Data. Advances in Heat Transfer: Supplement. Academic Press, New York, USA.

Shi, J., Qu, X., Qi, Z., Chen, J., 2011. Investigating performance of microchannel evaporators with different manifold structures. Int. J. Refrigeration 34 (1), 292-302.

Webb, R.L., Chung, K., 2005. Two-phase flow distribution to tubes of parallel flow air-cooled heat exchangers. Heat. Transf. Eng. 26 (4), 3-18. 